\title{
Oral Nicorandil for Prevention of Cardiac Death in Hemodialysis Patients without Obstructive Coronary Artery Disease: A Propensity-Matched Patient Analysis
}

\author{
Masato Nishimura ${ }^{a}$ Chikako Sakoda $^{b}$ Mayuko Murakawa ${ }^{b}$ Yu Okamoto ${ }^{c}$ \\ Toshiko Tokoro $^{\text {b }}$ Nodoka Sato $^{d}$ Masaya Nishidad ${ }^{d}$ Tetsuya Hashimoto ${ }^{d}$ \\ Hiroyuki Kobayashi $^{\text {e Satoru Yamazaki }}{ }^{f}$ Noriyuki Iwamoto $^{d}$ Hakuo Takahashig \\ Toshihiko Ono ${ }^{\mathrm{d}}$ \\ ${ }^{a}$ Cardiovascular Division, ${ }^{b}$ Division of Nephrology, ${ }^{\mathrm{C}}$ Division of Anesthesiology, and ${ }^{\mathrm{d}}$ Division of Urology, \\ Toujinkai Hospital, ${ }^{\mathrm{e} T o u j i n k a i ~ K a r a s u m a ~ C l i n i c, ~ a n d ~}{ }^{\mathrm{f}}$ Toujinkai Clinic, Kyoto, and ${ }^{9}$ Department of Clinical Sciences and \\ Laboratory Medicine, Kansai Medical University, Osaka, Japan
}

\section{Key Words}

Acute myocardial infarction $\cdot$ Heart failure $\cdot$ Ischemia $\cdot$

Microangiopathy $\cdot$ Preconditioning $\cdot$ Sudden death

\begin{abstract}
Background/Aims: We examined the potential of oral administration of nicorandil for protecting against cardiac death in hemodialysis patients without obstructive coronary artery disease. Methods: This study was based on a cohort study of 155 hemodialysis patients with angiographic absence of obstructive coronary lesions, with analysis performed in 100 propensity-matched patients (54 men and 46 women, $64 \pm 10$ years), including 50 who received oral administration of nicorandil ( $15 \mathrm{mg} /$ day, nicorandil group) and 50 who did not (control). The efficacy of nicorandil in preventing cardiac death was investigated. Results: Over a mean follow-up period of $5.3 \pm 1.9$ years, we observed 25 cardiac deaths among 100 propensity-matched patients, including 6 due to acute myocardial infarction, 11 due to heart failure, and 8 due to sudden cardiac death. The incidence of cardiac death was lower $(p<0.001)$ in the nicorandil group
\end{abstract}

$(4 / 50,8 \%)$ than in the control $(21 / 50,42 \%)$. On multivariate Cox hazard analysis, cardiac death was inversely associated with oral nicorandil (hazard ratio, 0.123; $p=0.0002$ ). On Kaplan-Meier analysis, cardiac death-free survival rates at 5 years were higher in the nicorandil group than in the control group (91.4 vs. 66.4\%). Conclusion: Oral nicorandil may inhibit cardiac death of hemodialysis patients without obstructive coronary artery disease.

Copyright $\odot 2011$ S. Karger AG, Basel

\section{Introduction}

Cardiac diseases are important causes of death in patients with end-stage renal disease on maintenance hemodialysis [1-3]. While coronary artery disease (CAD) is undoubtedly involved in cardiac death induced by acute myocardial infarction (MI) or congestive heart failure $(\mathrm{CHF})$ and in sudden cardiac death (SCD) $[4,5]$, cardiac death occurs in patients on hemodialysis without extant CAD. The 5-year cumulative incidences of cardiac death among patients on hemodialysis were 48.3 and $40.2 \%$, re-

\section{KARGER}

Fax +41613061234 E-Mail karger@karger.ch www.karger.com (c) 2011 S. Karger AG, Basel

$1660-2110 / 11 / 1194-0301 \$ 38.00 / 0$

Accessible online at:

www.karger.com/nec
Masato Nishimura, MD

Cardiovascular Division, Toujinkai Hospital

83-1, Iga, Momoyama-cho, Fushimi-ku

Kyoto 612-8026 (Japan)

Tel. +81 75622 1991, E-Mail mnishimura@tea.ocn.ne.jp 
Fig. 1. Entry and exclusion

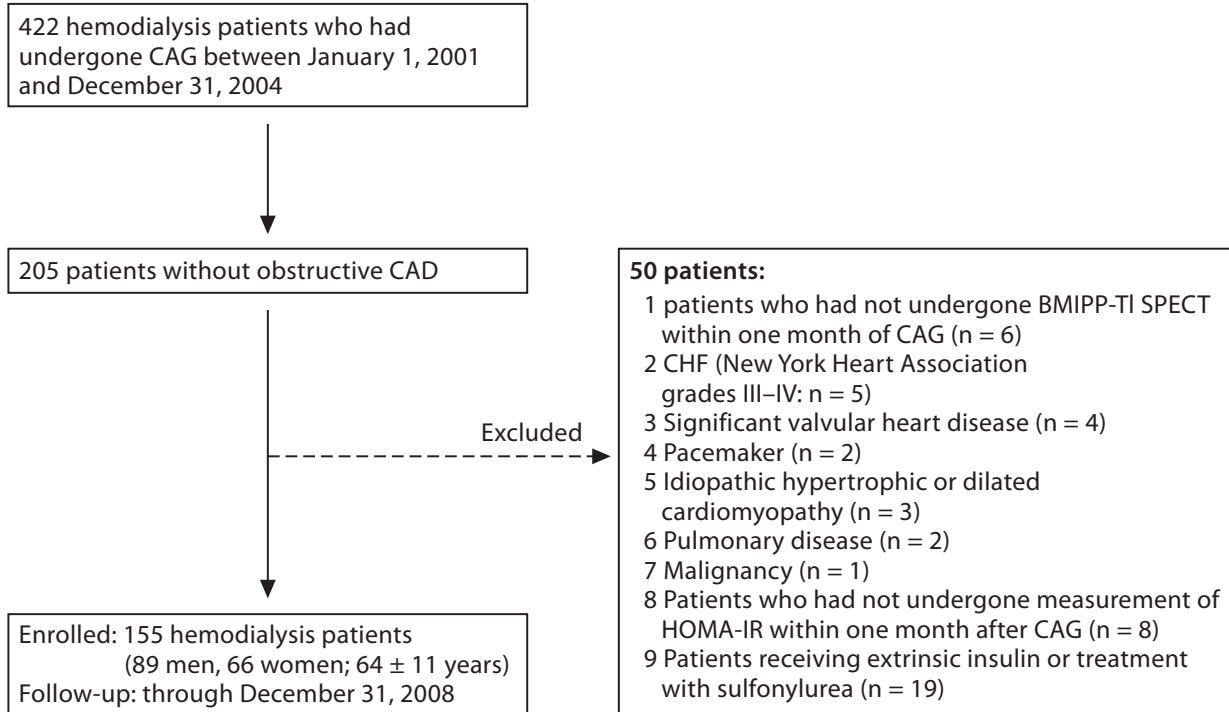
criteria for study participants.

spectively, in patients with and without prior CAD, although not all patients had undergone coronary angiography (CAG) [6]. We recently reported in a prospective cohort study that cardiac deaths occurred in approximately one fourth of hemodialysis patients without angiographic evidence of obstructive CAD [7]. However, few studies have investigated how cardiac death in hemodialysis patients without obstructive CAD can be inhibited.

Nicorandil, $\mathrm{N}$-(2-hydroxyethyl)-nicotinamide, is an antianginal drug that causes vasodilation of both epicardial arteries and microvessels, with little reduction in blood pressure [8]. These effects of nicorandil involve activation of adenosine triphosphate (ATP)-sensitive potassium $\left(\mathrm{K}_{\mathrm{ATP}}\right)$ channels and increase in the production of cyclic guanylate monophosphate [9]. In addition, nicorandil acts as a pharmacologic preconditioning agent for ischemia by opening mitochondrial $\mathrm{K}_{\mathrm{ATP}}$ channels [10]. The Impact of Nicorandil in Angina trial showed that oral administration of nicorandil was associated with significantly lower rates of cardiovascular accidents including cardiac death in patients with stable angina [11]. We reported the potential of oral nicorandil to inhibit the occurrence of major adverse cardiac events in asymptomatic hemodialysis patients [12]. Oral administration of nicorandil has been reported to inhibit cardiac events or cardiac death after coronary revascularization by percutaneous coronary artery intervention in patients on maintenance hemodialysis $[13,14]$. In the present study, we examined whether oral administration of nicorandil could inhibit cardiac death in hemodialysis patients without obstructive CAD.

\section{Methods}

\section{Patients}

This study was based on a cohort study designed to investigate the involvement of impaired myocardial fatty acid metabolism and insulin resistance in cardiac death of hemodialysis patients (ClinicalTrials.gov, NCT01068080). Details of this study are provided elsewhere [7]. Figure 1 summarizes entry and exclusion criteria for the study, which proceeded at three dialysis centers associated with the Toujinkai Group. Four hundred and twenty-two patients with end-stage renal disease on maintenance hemodialysis at the Toujinkai Group underwent CAG for the first time to determine the presence or absence of CAD between January 1, 2001, and December 31, 2004. No significant stenotic coronary lesions (diameter stenosis greater than 50\%) were identified in 205 of the 422 patients. Among them, 50 patients were excluded from the study for the reasons indicated in figure 1. Consequently, 155 hemodialysis patients without significant obstructive coronary lesions were enrolled in this cohort study (89 men and 66 women; mean age: $64 \pm 11$ years; mean duration of dialysis: $91 \pm 97$ months). The participants were enrolled at the time of homeostasis model assessment-insulin resistance (HOMA-IR) measurements (between January 1, 2001, and December 31, 2004), and followed through December 31, 2008 until the end point described below. 
Nicorandil was orally administered within one week of CAG through the end of the study to patients who had exhibited any of the following clinical signs or findings: (1) recurrent abrupt hypotension during dialysis, (2) transient ST segment depression on the electrocardiogram during dialysis, (3) new ST-T changes (including nonspecific changes) on routine electrocardiography, or (4) severely impaired myocardial fatty acid metabolism on imaging (iodine-123- $\beta$-methyl iodophenyl-pentadecanoic acid, BMIPP, summed scores of 12 or more). The first three of these findings are suggestive of the presence of myocardial ischemia in dialysis patients according to the K/DOQI guidelines [15], while the fourth finding may indicate risk of cardiac death in hemodialysis patients [16]. Of the 155 study patients, 77 exhibited one or more of these four findings: 67 patients agreed to undergo administration of nicorandil (nicorandil group), while the other $10 \mathrm{pa}-$ tients did not. These 10 patients and 78 patients who had not exhibited the above signs or findings and had not received administration of nicorandil were designated the non-nicorandil group. Nicorandil was never administered to patients of the non-nicorandil group during the study. No patients discontinued administration of nicorandil before the end point or end of the study. The dose for oral administration of nicorandil was uniformly $15 \mathrm{mg} /$ day, the approved dosage in Japan. Other cardiovascular drugs prescribed before the study were continued during it. Smoking was defined as 10 or more cigarettes per week and alcohol consumption as alcohol intake of $20 \mathrm{~g}$ or more per week. The Ethics Committee for Human Research of Toujinkai Hospital approved this study, and all patients provided written informed consent to all procedures associated with the study prior to participation. The study was performed in accordance with the principles of the Declaration of Helsinki.

\section{Coronary Angiography}

Experienced cardiologists performed quantitative CAG at the Department of Interventional Cardiology of Kyoto Second Red Cross Hospital using a validated automated edge-detection program (CCIP-310/W, CATHEX, Tokyo, Japan). Significant coronary artery stenosis was defined as stenosis $>50 \%$ diameter on CAG images.

\section{Radionuclide Imaging}

All patients underwent resting BMIPP and ${ }^{201}$ Thallium (Tl) dual single-photon emission computed tomography (SPECT) within one month before first CAG. Details of the dual BMIPPTl SPECT procedure are provided elsewhere [16-18]. Images were divided into 17 segments for semiquantitative analysis according to the standard myocardial segmentation for tomographic heart imaging established by the American Heart Association. The amount of radioactivity taken up by each segment was visually graded and assigned an uptake score of 0 (normal), 1 (mildly reduced), 2 (moderately reduced), 3 (severely reduced), or 4 (none). BMIPP and Tl SPECT scores for the 17 myocardial segments were designated the summed BMIPP and Tl scores, respectively. The interobserver and intraobserver variability in the summed scores at our institution was $6.8 \pm 1.4$ and $5.4 \pm$ $1.4 \%$, respectively [7]

\section{Echocardiography}

The patients underwent two-dimensionally guided echocardiography using a single ultrasonographic recorder (UF-8800,
Fukuda Denshi, Tokyo, Japan) within one month before CAG. Left ventricular dimensions and left ventricular ejection fraction were quantified using the biplanar Simpson's rule. Left ventricular mass was measured as recommended by the American Society of Echocardiography, normalized to body surface area, and described herein as left ventricular mass index.

Biochemical and Hematological Determinations

On a midweek dialysis day within 30 days after CAG, blood samples $(10 \mathrm{ml})$ were obtained in the morning from patients who had fasted overnight and rested for $10 \mathrm{~min}$. Hemoglobin (and hemoglobin A1c for diabetic patients), plasma concentrations of intact parathyroid hormone and B-type natriuretic hormone, and serum concentrations of calcium, inorganic phosphorus, albu$\mathrm{min}$, total cholesterol, and high-sensitivity C-reactive protein were determined.

\section{Assessment of Insulin Resistance}

We used fasting plasma glucose and fasting plasma insulin concentrations to calculate the HOMA-IR value as described by Mathews et al. [19] as fasting glucose concentration $(\mathrm{mmol} / \mathrm{l}) \times$ fasting insulin concentration $(\mu \mathrm{U} / \mathrm{ml}) / 22.5$. Blood samples were collected on the same day to measure other biochemical and hematological parameters.

\section{End Point}

All participants of this study had been followed in the hospital or clinics of the Toujinkai Group until the end point or the end of study (December 31,2008). The end point was cardiac-derived death (SCD or death due to acute MI or CHF). We defined SCD as death within $24 \mathrm{~h}$ of the time the patient was last seen alive in a normal state of health and for which cardiac diseases such as malignant arrhythmias or acute coronary syndrome were considered the cause. Cerebrovascular accidents were ruled out by postmortem examination. Acute MI was diagnosed when new abnormal Q waves appeared on electrocardiograms together with anterior chest pain or discomfort, when abnormal left ventricular wall motion was recognized on echocardiograms, and when serum concentrations of troponin-T and creatine phosphokinase-MB fraction were significantly elevated. Death due to CHF did not include death due to heart failure caused by acute MI. When the death of a patient occurred at home or away from home, or in the hospital or clinics of the Toujinkai Group, cardiologists and internists of Toujinkai Hospital confirmed the death and diagnosed cardiac death. In cases in which death of a patient occurred at Kyoto Second Red Cross Hospital due to acute MI, cardiologists of that hospital diagnosed acute MI as the cause of death.

\section{Statistical Analysis}

Values are the means $\pm \mathrm{SD}$. To guarantee maximum validity of this retrospective analysis, propensity scoring was used to match patients between the nicorandil $(n=67)$ and non-nicorandil $(n=88)$ groups. Propensity scoring can reduce bias resulting from the nonrandom nature of treatment assignment seen in observational studies [20]. The propensity score is the expected probability of receiving one treatment over another for a given patient, based on that patient's baseline characteristics. A logistic regression model of the actual treatment received is fit to the data, and the propensity score for each patient is then esti- 
Table 1. Clinical characteristics of the nicorandil and non-nicorandil groups

\begin{tabular}{|c|c|c|c|c|}
\hline & $\begin{array}{l}\text { Total } \\
(\mathrm{n}=155)\end{array}$ & $\begin{array}{l}\text { Control } \\
(\mathrm{n}=88)\end{array}$ & $\begin{array}{l}\text { Nicorandil } \\
(\mathrm{n}=67)\end{array}$ & $\begin{array}{l}\mathrm{p} \\
\text { value }\end{array}$ \\
\hline Age, years & $63.7 \pm 10.8$ & $64.4 \pm 11.1$ & $62.9 \pm 10.4$ & 0.396 \\
\hline Male & $89(57.4)$ & $51(58.0)$ & $38(56.7)$ & 0.877 \\
\hline Hemodialysis duration, months & $90.5 \pm 97.3$ & $88.9 \pm 95.9$ & $92.7 \pm 99.7$ & 0.811 \\
\hline Body mass index & $21.2 \pm 4.3$ & $20.2 \pm 4.2$ & $22.6 \pm 4.1$ & 0.0005 \\
\hline Smoking & $60(38.7)$ & $34(38.6)$ & $26(38.8)$ & 0.983 \\
\hline Alcohol & $60(38.7)$ & $31(35.2)$ & $29(43.3)$ & 0.308 \\
\hline Cardiothoracic ratio, $\%$ & $52.1 \pm 5.2$ & $52.6 \pm 5.2$ & $51.5 \pm 5.2$ & 0.207 \\
\hline Systolic blood pressure before dialysis, $\mathrm{mm} \mathrm{Hg}$ & $143.7 \pm 15.8$ & $144.5 \pm 15.9$ & $142.7 \pm 15.8$ & 0.502 \\
\hline Diastolic blood pressure before dialysis, $\mathrm{mm} \mathrm{Hg}$ & $79.0 \pm 17.5$ & $76.9 \pm 14.7$ & $81.7 \pm 20.4$ & 0.103 \\
\hline Diabetes mellitus & $59(38.1)$ & $35(39.8)$ & $24(35.8)$ & 0.616 \\
\hline $\mathrm{Kt} / \mathrm{V}_{\text {urea }}$ & $1.79 \pm 0.23$ & $1.81 \pm 0.24$ & $1.77 \pm 0.21$ & 0.299 \\
\hline Left ventricular ejection fraction, $\%$ & $63.3 \pm 14.6$ & $62.3 \pm 15.5$ & $64.6 \pm 13.3$ & 0.327 \\
\hline Left ventricular mass index, $\mathrm{g} / \mathrm{m}^{2}$ & $140.3 \pm 49.3$ & $138.8 \pm 46.1$ & $142.3 \pm 53.5$ & 0.661 \\
\hline Blood hemoglobin, g/l & $104.5 \pm 11.5$ & $104.4 \pm 12.2$ & $104.6 \pm 10.6$ & 0.890 \\
\hline Serum calcium, $\mathrm{mmol} / \mathrm{l}$ & $2.3 \pm 0.2$ & $2.3 \pm 0.2$ & $2.2 \pm 0.2$ & 0.239 \\
\hline Serum inorganic phosphorus, $\mathrm{mmol} / \mathrm{l}$ & $1.7 \pm 0.3$ & $1.3 \pm 0.4$ & $1.7 \pm 0.3$ & 0.355 \\
\hline Serum albumin, $g / 1$ & $37.8 \pm 3.4$ & $37.6 \pm 3.4$ & $38.1 \pm 3.4$ & 0.821 \\
\hline Serum total cholesterol, $\mathrm{mmol} / \mathrm{l}$ & $4.4 \pm 0.9$ & $4.4 \pm 0.9$ & $4.4 \pm 1.0$ & 0.976 \\
\hline Serum high-sensitivity C-reactive protein, mg/l & $3.8 \pm 2.9$ & $3.7 \pm 3.0$ & $4.0 \pm 2.8$ & 0.595 \\
\hline Plasma intact parathyroid hormone, ng/l, log & $2.2 \pm 0.3$ & $2.2 \pm 0.4$ & $2.3 \pm 0.3$ & 0.274 \\
\hline Plasma B-type natriuretic peptide, ng/l, log & $2.4 \pm 0.4$ & $2.4 \pm 0.4$ & $2.4 \pm 0.4$ & 0.971 \\
\hline BMIPP summed score & $9.6 \pm 8.6$ & $9.8 \pm 9.1$ & $9.3 \pm 7.9$ & 0.707 \\
\hline Tl summed score & $4.5 \pm 4.4$ & $4.4 \pm 4.3$ & $4.6 \pm 4.6$ & 0.715 \\
\hline $\mathrm{HOMA}-\mathrm{IR}, \mathrm{mmol} / \mathrm{l} \cdot \mu \mathrm{U} / \mathrm{ml}$ & $4.8 \pm 1.9$ & $4.8 \pm 2.0$ & $4.9 \pm 1.8$ & 0.803 \\
\hline \multicolumn{5}{|l|}{ Medications } \\
\hline$\alpha_{1}$-Blockers & $14(9.0)$ & $8(9.1)$ & $6(9.0)$ & 0.977 \\
\hline$\beta$-Blockers & $39(25.2)$ & $23(26.1)$ & $16(23.9)$ & 0.749 \\
\hline Calcium channel blockers & $44(28.4)$ & $24(27.3)$ & $20(29.9)$ & 0.724 \\
\hline Nitrates & $22(14.2)$ & $11(12.5)$ & $11(16.4)$ & 0.489 \\
\hline Angiotensin I-converting enzyme inhibitors & $4(2.6)$ & $2(2.3)$ & $2(3.0)$ & 0.782 \\
\hline Angiotensin II receptor blockers & $39(25.2)$ & $21(23.9)$ & $18(26.9)$ & 0.670 \\
\hline Antiplatelet drugs & $84(54.2)$ & $47(53.4)$ & $37(55.2)$ & 0.822 \\
\hline Anticoagulation drugs & $1(0.6)$ & $1(1.1)$ & 0 & 0.381 \\
\hline Statins & $34(21.9)$ & $15(17.0)$ & $19(28.4)$ & 0.092 \\
\hline Vitamin D & $91(58.7)$ & $53(60.2)$ & $38(56.7)$ & 0.663 \\
\hline Digoxin & $12(7.7)$ & $6(6.8)$ & $6(9.0)$ & 0.625 \\
\hline Class 1 antiarrhythmic drugs & $10(6.5)$ & $6(6.8)$ & $4(6.0)$ & 0.833 \\
\hline
\end{tabular}

Figures are means \pm SD or numbers with percentages in parentheses.

mated. Many covariates, in addition to higher-order terms and covariate interactions, can be condensed into a single scalar variable, the propensity score [21]. Thus, logistic regression analysis was used to develop the propensity score, and baseline data, including cardiothoracic ratio, diastolic blood pressure before dialysis, body mass index, and administration of statins were used as covariates. Patients in the nicorandil group and those in the non-nicorandil group were matched in a 1:1 ratio with 1 digit, based on the estimated propensity score for treatment with oral nicorandil. As a result, estimated propensity scores could be used to match 50 patients each from the nicorandil and non-nicorandil groups. The statistical analyses de- scribed below were performed for these 100 propensity-matched patients. The t test was used to compare means of continuous variables, and categorical data were analyzed using the $\chi^{2}$ test. Kaplan-Meier analysis and the log-rank test were used to examine survival. Multivariate analysis of prognosis was performed using the stepwise Cox proportional hazard model. Variables with $p$ values of $<0.2$ on univariate analysis were entered into multivariate analysis. $p$ values of $<0.05$ were considered significant. Individuals without knowledge of patient profiles and clinical data performed all statistical analyses. 
Table 2. Clinical characteristics of the subjects included in propensity analysis

\begin{tabular}{|c|c|c|c|c|}
\hline & $\begin{array}{l}\text { Total } \\
(\mathrm{n}=100)\end{array}$ & $\begin{array}{l}\text { Control } \\
(\mathrm{n}=50)\end{array}$ & $\begin{array}{l}\text { Nicorandil } \\
(\mathrm{n}=50)\end{array}$ & $\begin{array}{l}\mathrm{p} \\
\text { value }\end{array}$ \\
\hline Age, years & $64.2 \pm 10.3$ & $64.7 \pm 10.2$ & $63.6 \pm 10.5$ & 0.590 \\
\hline Male & $54(54.0)$ & $27(54.0)$ & $27(54.0)$ & 1.000 \\
\hline Hemodialysis duration, months & $94.0 \pm 101.6$ & $86.3 \pm 100.1$ & $101.8 \pm 103.5$ & 0.448 \\
\hline Body mass index & $21.5 \pm 4.0$ & $21.4 \pm 4.2$ & $21.6 \pm 3.9$ & 0.853 \\
\hline Smoking & $40(40.0)$ & $18(36.0)$ & $22(44.0)$ & 0.414 \\
\hline Alcohol & $35(35.0)$ & $15(30.0)$ & $20(40.0)$ & 0.295 \\
\hline Cardiothoracic ratio, $\%$ & $52.0 \pm 5.4$ & $52.1 \pm 5.5$ & $51.9 \pm 5.4$ & 0.883 \\
\hline Systolic blood pressure before dialysis, $\mathrm{mm} \mathrm{Hg}$ & $143.8 \pm 16.4$ & $145.4 \pm 15.9$ & $142.1 \pm 16.8$ & 0.310 \\
\hline Diastolic blood pressure before dialysis, $\mathrm{mm} \mathrm{Hg}$ & $78.7 \pm 14.9$ & $79.3 \pm 15.8$ & $78.1 \pm 14.0$ & 0.698 \\
\hline Diabetes mellitus & $38(38.0)$ & $22(44.0)$ & $16(32.0)$ & 0.216 \\
\hline $\mathrm{Kt} / \mathrm{V}_{\text {urea }}$ & $1.79 \pm 0.21$ & $1.76 \pm 0.23$ & $1.74 \pm 0.19$ & 0.624 \\
\hline Left ventricular ejection fraction, $\%$ & $63.3 \pm 14.4$ & $61.5 \pm 16.4$ & $65.0 \pm 12.0$ & 0.225 \\
\hline Left ventricular mass index, $\mathrm{g} / \mathrm{m}^{2}$ & $134.7 \pm 47.4$ & $130.8 \pm 44.4$ & $138.5 \pm 50.4$ & 0.422 \\
\hline Blood hemoglobin, g/l & $104.1 \pm 11.7$ & $105.0 \pm 13.4$ & $103.2 \pm 9.9$ & 0.451 \\
\hline Serum calcium, mmol/l & $2.3 \pm 0.2$ & $2.3 \pm 0.2$ & $2.3 \pm 0.2$ & 0.562 \\
\hline Serum inorganic phosphorus, $\mathrm{mmol} / \mathrm{l}$ & $1.7 \pm 0.4$ & $1.7 \pm 0.4$ & $1.7 \pm 0.3$ & 0.404 \\
\hline Serum albumin, $g / 1$ & $37.8 \pm 3.5$ & $37.6 \pm 3.4$ & $38.0 \pm 3.5$ & 0.567 \\
\hline Serum total cholesterol, $\mathrm{mmol} / \mathrm{l}$ & $4.3 \pm 0.9$ & $4.4 \pm 0.8$ & $4.2 \pm 0.9$ & 0.546 \\
\hline Serum high-sensitivity C-reactive protein, $\mathrm{mg} / \mathrm{l}$ & $4.0 \pm 3.0$ & $4.2 \pm 3.1$ & $3.7 \pm 2.9$ & 0.450 \\
\hline Plasma intact parathyroid hormone, ng/l, log & $227.9 \pm 165.2$ & $2.3 \pm 0.3$ & $2.2 \pm 0.3$ & 0.974 \\
\hline Plasma B-type natriuretic peptide, ng/l, log & $2.4 \pm 0.4$ & $2.4 \pm 0.4$ & $2.5 \pm 0.3$ & 0.211 \\
\hline BMIPP summed score & $9.2 \pm 8.4$ & $9.4 \pm 9.1$ & $9.0 \pm 7.7$ & 0.823 \\
\hline Tl summed score & $4.4 \pm 4.1$ & $4.1 \pm 3.8$ & $4.8 \pm 4.4$ & 0.357 \\
\hline $\mathrm{HOMA}-\mathrm{IR}, \mathrm{mmol} / \mathrm{l} \cdot \mu \mathrm{U} / \mathrm{ml}$ & $4.8 \pm 1.8$ & $4.9 \pm 2.0$ & $4.8 \pm 1.5$ & 0.677 \\
\hline \multicolumn{5}{|l|}{ Medications } \\
\hline$\alpha_{1}$-Blockers & $9(9.0)$ & $6(12.0)$ & $3(6.0)$ & 0.487 \\
\hline$\beta$-Blockers & $28(28.0)$ & $15(30.0)$ & $13(26.0)$ & 0.656 \\
\hline Calcium channel blockers & $22(22.0)$ & $13(26.0)$ & $9(18.0)$ & 0.334 \\
\hline Nitrates & $26(26.0)$ & $17(34.0)$ & $9(18.0)$ & 0.585 \\
\hline Angiotensin I-converting enzyme inhibitors & $2(2.0)$ & $1(2.0)$ & $1(2.0)$ & 1.000 \\
\hline Angiotensin II receptor blockers & $25(25.0)$ & $13(26.0)$ & $12(24.0)$ & 0.817 \\
\hline Antiplatelet drugs & $57(57.0)$ & $26(52.0)$ & $31(62.0)$ & 0.313 \\
\hline Anticoagulation drugs & 0 & 0 & 0 & \\
\hline Statins & $19(19.0)$ & $10(20.0)$ & $9(18.0)$ & 0.799 \\
\hline Vitamin D & $56(56.0)$ & $27(54.0)$ & $29(58.0)$ & 0.691 \\
\hline Digoxin & $9(9.0)$ & $4(8.0)$ & $5(10.0)$ & 0.730 \\
\hline Class 1 antiarrhythmic drugs & $8(8.0)$ & $4(8.0)$ & $4(8.0)$ & 1.000 \\
\hline
\end{tabular}

Figures are means \pm SD or numbers with percentages in parentheses.

\section{Results}

During follow-up of 155 patients on hemodialysis, we observed 42 cardiac deaths (7 acute MI, 18 CHF, 17 SCD) over a mean of $5.1 \pm 2.0$ years. Table 1 shows the baseline clinical characteristics of all participants, those administered nicorandil (nicorandil group: $n=67$ ), and those not administered nicorandil (non-nicorandil group: $\mathrm{n}=$ 88). Mean body mass index was higher in the nicorandil group than in the non-nicorandil group, and rate of pre- scription of statins tended to be higher in the nicorandil than the non-nicorandil group. To decrease bias, we performed a propensity-matched analysis as described above.

\section{Cardiac Death in Propensity-Matched Patients}

Estimated propensity scores matched 50 patients each from the nicorandil and non-nicorandil groups (54 men and 46 women; age, $64 \pm 10$ years; duration of dialysis, $94 \pm 104$ months). The baseline clinical characteristics of the patients listed in table 2 did not differ between the 
Table 3. Univariate Cox hazard analysis of cardiac death

\begin{tabular}{|c|c|c|c|}
\hline & $\begin{array}{l}\text { Hazard } \\
\text { ratio }\end{array}$ & $\begin{array}{l}95 \% \text { confidence } \\
\text { interval }\end{array}$ & $\mathrm{p}$ \\
\hline Age (1 year) & 1.048 & $1.012-1.087$ & 0.001 \\
\hline Male $(1=$ yes, $0=$ no $)$ & 1.119 & $0.508-2.467$ & 0.780 \\
\hline Duration of hemodialysis (1 month) & 1.001 & $0.997-1.005$ & 0.762 \\
\hline Body mass index (1) & 0.955 & $0.869-1.049$ & 0.337 \\
\hline Smoking $(1=$ yes, $0=$ no $)$ & 0.978 & $0.439-2.177$ & 0.956 \\
\hline $\operatorname{Alcohol}(1=$ yes, $0=$ no $)$ & 0.529 & $0.211-1.327$ & 0.175 \\
\hline Cardiothoracic ratio $(1 \%)$ & 1.057 & $0.987-1.133$ & 0.115 \\
\hline Systolic blood pressure before dialysis (1 mm Hg) & 0.983 & $0.959-1.007$ & 0.260 \\
\hline Diastolic blood pressure before dialysis ( $1 \mathrm{~mm} \mathrm{Hg}$ ) & 0.995 & $0.966-1.024$ & 0.731 \\
\hline Diabetes mellitus $(1=$ yes, $0=$ no $)$ & 1.138 & $0.511-2.535$ & 0.751 \\
\hline $\mathrm{Kt} / \mathrm{V}_{\text {urea }}(1)$ & 0.692 & $0.092-5.199$ & 0.720 \\
\hline Left ventricular ejection fraction (1\%) & 0.964 & $0.942-0.987$ & 0.002 \\
\hline Left ventricular mass index $\left(1 \mathrm{~g} / \mathrm{m}^{2}\right)$ & 0.997 & $0.988-1.006$ & 0.459 \\
\hline Blood hemoglobin $(1 \mathrm{~g} / \mathrm{l})$ & 1.002 & $0.969-1.035$ & 0.922 \\
\hline Serum calcium $(1 \mathrm{mmol} / \mathrm{l})$ & 0.874 & $0.093-8.174$ & 0.906 \\
\hline Serum inorganic phosphorus $(1 \mathrm{mmol} / \mathrm{l})$ & 0.541 & $0.171-1.711$ & 0.296 \\
\hline Serum albumin $(1 \mathrm{~g} / \mathrm{l})$ & 0.964 & $0.865-1.074$ & 0.509 \\
\hline Serum total cholesterol $(1 \mathrm{mmol} / \mathrm{l})$ & 0.903 & $0.577-1.412$ & 0.654 \\
\hline Serum high-sensitivity C-reactive protein $(1 \mathrm{mg} / \mathrm{l})$ & 0.946 & $0.823-1.088$ & 0.438 \\
\hline Plasma intact parathyroid hormone (1 ng/l, log) & 1.523 & $0.452-5.137$ & 0.497 \\
\hline Plasma B-type natriuretic peptide ( $1 \mathrm{ng} / \mathrm{l}, \mathrm{log})$ & 0.497 & $0.170-1.450$ & 0.201 \\
\hline BMIPP summed score (1) & 1.090 & $1.058-1.123$ & 0.0001 \\
\hline Tl summed score $(1)$ & 1.162 & $1.082-1.249$ & 0.0001 \\
\hline HOMA-IR $(1 \mathrm{mmol} / \mathrm{l} \cdot \mu \mathrm{U} / \mathrm{ml})$ & 1.476 & $1.244-1.752$ & 0.0001 \\
\hline$\alpha_{1}$-Blockers $(1=$ yes, $0=$ no $)$ & 0.767 & $0.181-3.254$ & 0.719 \\
\hline$\beta$-Blockers $(1=$ yes, $0=$ no $)$ & 1.151 & $0.496-2.672$ & 0.743 \\
\hline Calcium channel blockers ( $1=$ yes, $0=$ no $)$ & 1.333 & $0.556-3.193$ & 0.519 \\
\hline Nitrates $(1=$ yes, $0=$ no $)$ & 0.914 & $0.314-2.665$ & 0.869 \\
\hline Angiotensin I-converting enzyme inhibitors $(1=$ yes, $0=$ no $)$ & 2.451 & $0.331-18.165$ & 0.380 \\
\hline Angiotensin II receptor blockers $(1=$ yes, $0=$ no $)$ & 1.529 & $0.660-3.546$ & 0.322 \\
\hline Nicorandil $(1=$ yes, $0=$ no $)$ & 0.157 & $0.054-0.459$ & 0.0007 \\
\hline Antiplatelet drugs $(1=$ yes, $0=$ no $)$ & 0.976 & $0.443-2.151$ & 0.952 \\
\hline Statins $(1=$ yes, $0=$ no $)$ & 0.817 & $0.280-2.182$ & 0.712 \\
\hline Vitamin D $(1=$ yes, $0=$ no $)$ & 0.760 & $0.346-1.669$ & 0.495 \\
\hline $\operatorname{Digoxin}(1=$ yes, $0=$ no $)$ & 1.434 & $0.427-4.817$ & 0.560 \\
\hline Class 1 antiarrhythmic drugs $(1=$ yes, $0=$ no $)$ & 0.396 & $0.053-2.929$ & 0.364 \\
\hline
\end{tabular}

nicorandil and control groups. During follow-up of these 100 patients for $5.3 \pm 1.9$ years, cardiac deaths occurred in 25 patients (6 acute MI, 11 CHF, 8 SCD). Cardiac death occurred in 4 patients of the nicorandil group (8\%) and 21 of the control (42\%), whereas non-cardiac death occurred in 8 patients of the nicorandil group (16\%) and 7 patients of the control (14\%). All 6 patients who died of acute MI were in the control group. The 4 cardiac deaths observed in the nicorandil group included 3 due to $\mathrm{CHF}$ and 1 due to SCD.

\section{Risk Analysis of Cardiac Death}

On univariate Cox hazard analysis, age, left ventricular ejection fraction, HOMA-IR, BMIPP or Tl summed scores, and administration of nicorandil were significantly associated with the occurrence of cardiac death (table 3). On stepwise Cox hazard analysis among these factors and other factors with $\mathrm{p}<0.2$ on univariate Cox hazard analysis (history of alcohol consumption and cardiothoracic ratio), BMIPP summed score, Tl summed score, and administration of nicorandil were significantly associated with cardiac death (table 4). Kaplan-Meier 
Fig. 2. Cardiac death-free survival rates in the propensity-matched nicorandil $(\mathrm{n}=$ $50)$ and control groups $(n=50) \cdot p=0.0001$, log-rank test.

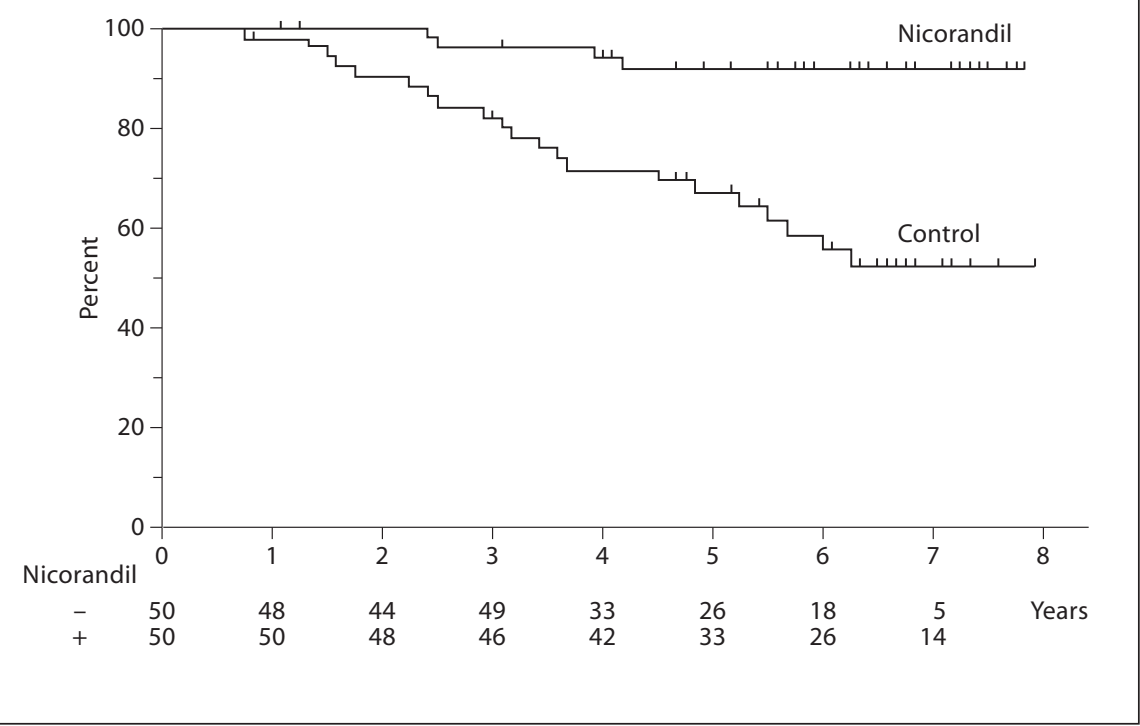

Table 4. Stepwise Cox hazard analysis of cardiac death

\begin{tabular}{llll}
\hline & $\begin{array}{l}\text { Hazard } \\
\text { ratio }\end{array}$ & $\begin{array}{l}\text { 95\% confidence } \\
\text { interval }\end{array}$ & $\mathrm{p}$ \\
\hline BMIPP summed score (1) & 1.086 & $1.039-1.136$ & 0.0003 \\
Tl summed score $(1)$ & 1.096 & $0.987-1.216$ & 0.0870 \\
Nicorandil $(1=$ yes, $0=$ no) & 0.123 & $0.041-0.368$ & 0.0002 \\
\hline
\end{tabular}

survival estimates revealed that cardiac death-free survival rates at 5 years were 91.4 and $66.4 \%$ for patients with and without nicorandil, respectively (fig. 2).

\section{Discussion}

Oral administration of nicorandil particularly inhibited death due to acute MI. In our previous study, oral nicorandil did not reduce the incidence of acute MI, but significantly inhibited death due to acute MI in asymptomatic hemodialysis patients [12]. Nicorandil acts as a pharmacologic preconditioning agent by opening mitochondrial $\mathrm{K}_{\mathrm{ATP}}$ channels and thus enhancing the tolerance of the heart to subsequent ischemia [10]. In addition, nicorandil improves endogenous fibrinolytic activity by increasing circulating plasminogen activator inhibitor [22] and inhibits cardiac sympathetic activity [23] and ox- idative stress-induced apoptosis in myocardial cells [24]. Recently, Izumiya et al. [25] reported that long-term oral administration of nicorandil stabilizes coronary plaque in patients with stable angina pectoris and in Apo-E-deficient mice by mechanisms different from those of statins. Oral administration of nicorandil may have reduced the extent of myocardial injury in acute coronary syndrome as a result of the pharmacologic effects described above, resulting in reduction of death due to acute MI.

Oral administration of nicorandil also inhibited the occurrence of SCD. SCD accounts for approximately one fourth of all-cause mortality in dialysis patients [26]. The main causes of SCD are believed to be hemodynamic collapse due to malignant arrhythmias such as ventricular fibrillation [27] as well as cardiogenic shock due to acute coronary syndrome. In our previous study [13], oral administration of nicorandil strongly inhibited the occurrence of SCD in hemodialysis patients who had undergone coronary revascularization by percutaneous coronary artery intervention. Nicorandil might have decreased SCD by interfering with the pathogenic mechanisms responsible for SCD of dialysis patients.

Intramyocardial arteriolar thickening, reduced capillary density, and myocardial fibrosis are pathological characteristics of the hearts of dialysis patients $[28,29]$. Such myocardial abnormalities readily produce myocardial microcirculatory disorders. The existence of histologically proven microvasculopathy has been reported to increase mortality after heart transplantation by induc- 
ing fatal cardiac events [30]. Dikow et al. [31] reported that tolerance of the heart to subsequent ischemia decreased in rats with impaired renal function, and that the size of myocardial infarcts induced by reperfusion ischemia was larger in rats with renal failure than in those without it. They speculated that myocardial microcirculatory disturbance was involved in the decreased tolerance to ischemia in rats with impaired renal function. Experimental models of microangiopathy induced by coronary microembolization exhibited arrhythmias leading to sudden death [32, 33]. Nicorandil exhibits a vasodilatory effect on coronary arterial microvessels $<100 \mu \mathrm{m}$ in diameter by opening $\mathrm{K}_{\mathrm{ATP}}$ channels [34]. Nicorandil improved microvascular abnormalities, as assessed by ${ }^{201}$ Tl myocardial perfusion imaging and echocardiographic determination of left ventricular function, in patients with ischemic cardiomyopathy [23]. The effects of nicorandil on the myocardial microcirculation are expected to reduce SCD by inhibiting the occurrence of malignant arrhythmias or cardiogenic shock in hemodialysis patients with acute coronary syndrome.

This study had several limitations. First, this was a retrospective study, using propensity-matched patient analysis. Although many large observational cohort studies have used propensity-matched patient analysis to minimize selection bias [20,21], we could not fully eliminate selection bias since the sample size was small. Relationships observed between oral nicorandil and cardiac death cannot be concluded to be causal. Second, we used CAG to confirm the presence of suspected myocardial ischemia. 'Without significant obstructive CAD' does not necessarily mean that the epicardial coronary arteries are normal. Since histopathological and intravascular ultrasound studies have demonstrated the propensity of angiography to underestimate lesion severity $[35,36]$, we cannot exclude the possibility that some angiographically nonsignificant lesions were flow-limiting. Third, the cumulative cardiogenic and all-cause mortalities of our population for about 5 years were 25 and $40 \%$, respectively, and apparently lower than those previously reported in other countries. Absence of obstructive CAD in the participants may be one of the reasons for the low mortality. Elimination of patients with CHF of NYHA grades III-IV, significant valvular heart disease, permanent pacemaker implantation, pulmonary diseases, idiopathic cardiomyopathy, or malignancy from study participants (fig. 1) could be another reason. Racial differences, a non-increased incidence of diabetes (38\%), the complete lack of withdrawal of patients from dialysis, and adequate dialysis as indicated by high mean $\mathrm{Kt} / \mathrm{V}_{\text {urea }}(1.79 \pm 0.21)$ might have contributed to re- ducing the mortality of our dialysis population. Lastly, the mean age of this study's participants was high, at 64 years among 100 propensity-matched patients, and advanced age is generally an independent risk factor for cardiac death. The results obtained in this study may thus not be applicable to all hemodialysis patients.

Cardiac death occurs at high incidence among hemodialysis patients without CAD. The results of this study indicate the efficacy of oral administration of nicorandil in inhibiting cardiac death, particularly acute MI death and SCD, in hemodialysis patients without significant stenotic CAD. Pharmacological effects such as preconditioning to ischemia, stabilization of coronary plaque, and improvement of impaired myocardial microcirculation may play roles in reducing cardiac death among hemodialysis patients administered oral nicorandil. Oral nicorandil may contribute to improving the survival of hemodialysis patients without obstructive CAD by inhibiting the occurrence of cardiac death. Since this is a retrospective study, we could not clearly determine the clinical value of oral nicorandil in prevention of cardiac death. Large, prospective, randomized clinical trials are needed to establish the clinical usefulness of oral nicorandil among this population.

\section{Acknowledgments}

The authors thank Naoto Inoue, MD, of the Sendai Kosei Hospital, and Hiroshi Fujita, MD, and the staff of the Department of Interventional Cardiology at Kyoto Second Red Cross Hospital for performing coronary angiography and cardiac disease assessment.

\section{Disclosure Statement}

None.

\section{References}

1 Collins AJ, Foley RN, Herzog C, Chavers B, Gilbertson D, Ishani A, Kasiske B, Liu J, Mau LW, McBean M, Murray A, St Peter W, Guo H, Gustafson S, Li Q, Li S, Li S, Peng Y, Qiu Y, Roberts T, Skeans M, Snyder J, Solid C, Wang C, Weinhandl E, Zaun D, Arko C, Chen SC, Dalleska F, Daniels F, Dunning S, Ebben J, Frazier E, Hanzlik C, Johnson R, Sheets D, Wang X, Forrest B, Constantini E, Everson S, Eggers P, Agodoa L: US Renal Data System 2010 Annual Data Report. Am J Kidney Dis 2011;57(suppl 1):e1-e526. 
$\checkmark 2$ Ansell D, Roderick P, Hodsman A, Ford D, Steenkamp R, Tomson C: UK Renal Registry 12th annual report (December 2009): Chapter 7. Survival and causes of death of UK adult patients on renal replacement therapy in 2008: national and centre-specific analyses. Nephron Clin Pract 2009;111:c113c139.

3 Nakai S, Suzuki K, Masakane I, Wada A, Itami N, Ogata S, Kimata N, Shigematsu T, Shinoda T, Syouji T, Taniguchi M, Tsuchida K, Nakamoto H, Nishi S, Nishi H, Hashimoto S, Hasegawa T, Hanafusa N, Hamano T, Fujii N, Marubayashi S, Morita O, Yamagata K, Wakai K, Watanabe Y, Iseki K, Tsubakihara Y: An overview of regular dialysis treatment in Japan (as of 31 December 2008). Ther Apher Dial 2010;14:505-540.

4 Stack AG, Bloembergen WE: Prevalence and clinical correlates of coronary artery disease among new dialysis patients in the United States: a cross-sectional study. J Am Soc Nephrol 2001;12:1516-1523.

5 Rostand SG, Rutsky EA: Ischemic heart disease in chronic renal failure: management considerations. Semin Dial 1989;2:98-101.

-6 Trivedi H, Xiang Q, Klein JP: Risk factors for non-fatal myocardial infarction and cardiac death in incident dialysis patients. Nephrol Dial Transplant 2009;24:258-266.

7 Nishimura M, Tsukamoto K, Tamaki N, Kikuchi K, Iwamoto N, Ono T: Risk stratification for cardiac death of hemodialysis patients without obstructive coronary artery disease. Kidney Int 2011;79:363-371.

8 Taira N, Satoh K, Yanagisawa T, Imai Y, Hiwatari M: Pharmacological profile of a new coronary vasodilator drug, 2-nicotinamidoethyl nitrate (SG-75). Clin Exp Pharmacol Physiol 1979;6:301-316.

-9 Kukovetz WR, Holzmann S, Braida C, Pöch G: Dual mechanism of the relaxing effect of nicorandil by stimulation of cyclic GMP formation and by hyperpolarization. J Cardiovasc Pharmacol 1991;17:627-633.

$\checkmark 10$ Lee TM, Su SF, Chou TF, Lee YT, Tsai CH: Loss of preconditioning by attenuated activation of myocardial ATP-sensitive potassium channels in elderly patients undergoing coronary angioplasty. Circulation 2002;105: 334-340.

11 IONA Study Group: Effect of nicorandil on coronary events in patients with stable angina: the Impact Of Nicorandil in Angina (IONA) randomized trial. Lancet 2002;359: 1269-1275.

12 Nishimura M, Tokoro T, Nishida M, Hashimoto T, Kobayashi H, Yamazaki S, Imai R, Okino K, Iwamoto N, Takahashi H, Ono T: Clinical potential of nicorandil to inhibit major cardiac events in hemodialysis patients with suspected myocardial ischemia. Nephron Clin Pract 2009;111:c212-c221.

13 Nishimura M, Tokoro T, Nishida M, Hashimoto T, Kobayashi H, Imai R, Yamazaki S, Okino K, Iwamoto N, Takahashi H, Ono T:
Oral nicorandil to reduce cardiac death after coronary revascularization in hemodialysis patients: a randomized trial. Am J Kidney Dis 2009;54:307-317.

14 Ishii H, Toriyama T, Aoyama T, Takahashi H, Yamada S, Kasuga H, Ichimiya S, Kanashiro M, Mitsuhashi H, Maruyama S, Matsuo S, Naruse K, Matsubara T, Murohara T: Efficacy of oral nicorandil in patients with endstage renal disease: a retrospective chart review after coronary angioplasty in Japanese patients receiving hemodialysis. Clin Ther 2007;29:110-122.

$15 \mathrm{~K} / \mathrm{DOQI}$ Workgroup: K/DOQI clinical practice guidelines for cardiovascular disease in dialysis patients. Am J Kidney Dis 2005;45(suppl 3):S1-S153.

-16 Nishimura M, Tsukamoto K, Hasebe N, Tamaki N, Kikuchi K, Ono T: Prediction of cardiac death in hemodialysis patients by myocardial fatty acid imaging. J Am Coll Cardiol 2008;51:139-145.

17 Nishimura M, Hashimoto T, Kobayashi H, Fukuda T, Okino K, Yamamoto N, Fujita H, Inoue N, Nishimura T, Ono T: Myocardial scintigraphy using a fatty acid analogue detects coronary artery disease in hemodialysis patients. Kidney Int 2004;66:811-819.

18 Nishimura M, Tokoro T, Nishida M, Hashimoto T, Kobayashi H, Yamazaki S, Imai R, Okino K, Takahashi H, Ono T: Myocardial fatty acid imaging identifies a group of hemodialysis patients at high risk for cardiac death after coronary revascularization. Kidney Int 2008;74:513-520.

19 Matthews DR, Hosker JP, Rudenski AS, Naylor BA, Treacher DF, Turner RC: Homeostasis model assessment: insulin resistance and beta-cell function from fasting plasma glucose and insulin concentrations in man. Diabetologia 1985;28:412-419.

20 Rubin DB: Estimating causal effects from large data sets using propensity scores. Ann Intern Med 1997;127:757-763.

21 D’Agostino PB Jr: Propensity score methods for bias reduction in the comparison of a treatment to a non-randomized control group. Stat Med 1998;17:2265-2281.

22 Sakamoto T, Kaikita K, Miyamoto S, Kojima S, Sugiyama S, Yoshimura M, Ogawa H: Effects of nicorandil on endogenous fibrinolytic capacity in patients with coronary artery disease. Circ J 2004;68:232-235.

23 Kasama S, Toyama T, Hatori T, Kumakura H, Takayama Y, Ichikawa S, Suzuki T, Kurabayashi M: Comparative effects of nicorandil with isosorbide mononitrate on cardiac sympathetic nerve activity and left ventricular function in patients with ischemic cardiomyopathy. Am Heart J 2005;150: 477.e1-477.e8.

24 Nagata K, Obata K, Odashima M, Yamada A, Somura F, Nishizawa T, Ichihara S, Izawa H, Iwase M, Hayakawa A, Murohara T, Yokota M: Nicorandil inhibits oxidative stress-induced apoptosis in cardiac myocytes through activation of mitochondrial ATP-sensitive potassium channels and a nitrate-like effect. J Mol Cell Cardiol 2003;35:1505-1512.

- 25 Izumiya Y, Kojima S, Kojima S, Araki S, Usuku H, Matsubara J, Sakamoto K, Tsujita K, Nagayoshi Y, Kaikita K, Sugiyama S, Ogawa $\mathrm{H}$ : Long-term use of oral nicorandil stabilizes coronary plaque in patients with stable angina pectoris. Atherosclerosis 2011;214:415421.

26 Cheung AK, Sarnak MJ, Yan G, Berkoben M, Heyka R, Kaufman A, Lewis J, Rocco M, Toto R, Windus D, Ornt D, Levey AS: Cardiac diseases in maintenance hemodialysis patients: results of the HEMO study. Kidney Int 2004; 65:2380-2389.

27 Demirovic J, Myerburg RJ: Epidemiology of sudden coronary death: an overview. Prog Cardiovasc Dis 1994;37:39-48.

28 Barenbrock M, Spieker C, Laske V, Heidenreich S, Hohage H, Bachmann J, Hoeks AP, Rahn KH: Studies of vessel wall properties in hemodialysis patients. Kidney Int 1994;45: 1397-1400.

29 Amann K, Breitbach M, Ritz E, Mall G: Myocyte/capillary mismatch in the heart of uremic patients. J Am Soc Nephrol 1998;9:10181022 .

30 Hiemann NE, Wellnhofer E, Knosalla C, Lehmkuhl HB, Stein J, Hetzer R, Meyer R: Prognostic impact of microvasculopathy on survival after heart transplantation: evidence form 9713 endomyocardial biopsies. Circulation 2007;16:1274-1282.

- 31 Dikow R, Kihm LP, Zeier M, Kapitza J, Törnig J, Amann K, Tiefenbacher C, Ritz E: Increased infarct size in uremic rats: reduced ischemia tolerance? J Am Soc Nephrol 2004; 15:1530-1536.

- 32 Agress CM, Rosenberg MJ, Jacobs HI, Binder MJ, Schneiderman A, Clark WG: Protracted shock in the closed-chest dog following coronary embolization with graded microspheres. Am J Physiol 1952;170:536-549.

-33 Jacobey JA, Taylor WJ, Smith GT, Gorlin R, Harken DE: A new therapeutic approach to acute coronary occlusion. I. Production of standardized coronary occlusion with microspheres. Am J Cardiol 1962;9:60-73.

34 Akai K, Wang Y, Sato K, Sekiguchi N, Sugimura A, Kumagai T, Komaru T, Kanatsuka $\mathrm{H}$, Shirato K: Vasodilatory effect of nicorandil on coronary arterial microvessels: its dependency on vessel size and the involvement of the ATP-sensitive potassium channels. J Cardiovasc Pharmacol 1995;26:541547.

- 35 Arnett EN, Isner JM, Redwood DR, et al: Coronary artery narrowing in coronary heart disease: comparison of cineangiographic and necropsy findings. Ann Intern Med 1979;91:350-356.

- 36 Porter TR, Sears T, Xie F, et al: Intravascular ultrasound study of angiographically mildly diseased coronary arteries. J Am Coll Cardiol 1993;22:1858-1865. 